\title{
The Healthy Kids Initiative: Results from the First 2000 Participants
}

This article was published in the following Dove Press journal:

Patient Preference and Adherence

\section{Mark Lemstra' \\ Marla Rogers ${ }^{2}$}

'Alliance Wellness and Rehabilitation Inc., Moose Jaw, Saskatchewan, Canada; ${ }^{2}$ The Canadian Hub for Applied and Social Research, University of Saskatchewan, Saskatoon, Canada
Correspondence: Marla Rogers

Canadian Hub for Applied and Social Research, University of Saskatchewan, Saskatoon, SK S7N 5A5, Canada Email marla.rogers@usask.ca
Purpose: The comprehensive and free Healthy Kids Initiative (HKI) was developed with key features including social support, family support, and cognitive behavior education in order to promote program completion and improve health outcomes among youth. The first objective was to determine program completion rates and independent risk indicators for non-completion. The second objective was to determine the 12-week impact of the Healthy Kids Initiative on aerobic fitness, depressed mood and health-related quality of life.

Patients and Methods: Obese youth (ages 10-17) were referred to a community-based, multidisciplinary, free program by their doctor or pediatrician. Each participant was requested to attend the program with a "buddy" and complete three social support contracts with family and friends to support their behavioral modifications. The program duration was 12 weeks with physical activity, dietary, and cognitive behavior education sessions. Those who completed the program, and those who did not, were compared across socioeconomic variables, age, gender, depressed mood and aerobic fitness.

Results: Across five cohorts, 1789 of 1995 youth completed the program (89.7\% completion rate). Five referred youth never started. Independent risk indicators associated with noncompletion included older age (OR 3.07, 95\% CI 2.26-4.17; $<<0.001$ ), mother with a nonprofessional occupation (OR 1.84, 95\% CI 1.22-2.78; $\mathrm{p}=0.004$ ), and living in a low-income neighborhood (OR 9.37, 95\% CI 5.61-15.65; $<<0.001$ ). There were significant improvements from baseline for aerobic fitness (mCAFT score 35.84 to $55.72 \mathrm{~mL} \times \mathrm{kg}^{-1} \times \mathrm{min}^{-1}$; $\mathrm{p}<0.001$ ), depressed mood (mean CES-D 12 score 21.47 to $17.40 ; \mathrm{p}<0.001$ ), and healthrelated quality of life (mean SF-12 score 23.4 to 33.8 ; $\mathrm{p}<0.001$ ).

Conclusion: The HKI program had high completion rates and early success in improving outcomes. Knowing the independent risk indicators for non-completion will allow for program revision to help at-risk participants complete the program.

Keywords: adolescent, community-based, obese, aerobic fitness, adherence, physical activity

\section{Introduction}

There is little doubt that being overweight or obese in youth is a significant public health concern. According to an analysis of objective measures of body mass index (BMI) as well as self-reported data of height and weight among Canadian youth, $23.3 \%$ of children were overweight or obese in $1978 / 79$, and the prevalence increased to $31.4 \%$ by $2012 /$ 13. ${ }^{1}$ Obesity prevalence climbed from $12.3 \%$ in 2004 to $16.6 \%$ in $2012 / 13$ among youth 12-17 years. ${ }^{1}$ This trend has been the target of various public health and research initiatives to increase physical activity and promote healthier diets. ${ }^{2}$

The implications for obesity in youth are serious. A 2015 study by the American Heart Association found early signs of cardiovascular disease in obese children when compared to non-obese children. ${ }^{3}$ Further, the life expectancy of adults across 
high-income countries has recently declined, with obesity cited as one contributing cause for the reduction. ${ }^{4}$ The psychological implications are also important, with obesity in youth as a risk factor for depression and anxiety. One study found a $43 \%$ increased risk of depression and anxiety among obese female youth and a 33\% increased risk among obese male youth. ${ }^{5}$

Numerous programs to reduce weight in obese or overweight adolescents have been developed in the past 20 years, with varying degrees of success in reducing weight, ${ }^{6-9}$ improving body composition, ${ }^{9}$ and even improving mental health and quality of life. ${ }^{78}$ However, many of these programs have had moderate to high rates of attrition. For example, one study found attrition rates ranging from $27 \%$ at 12 -weeks to $73 \%$ at $9-12$ months. ${ }^{10}$ Without paying due attention to adherence and drop-out, well-designed interventions are limited in their effectiveness.

Enough research exists on improving physical activity in youth for a group of researchers to have developed ten practical lessons for generating success in programs designed to increase physical activity rates in overweight and obese children and adolescents. ${ }^{11}$ These supports include parent social support, applying a multidisciplinary approach, invoking a sense of fun, including variety, promoting a welcoming setting, and accounting for the individual physical and psychosocial characteristics of the participants. ${ }^{11}$

The Healthy Kids Initiative (HKI) is a comprehensive behavior modification program aimed at obese youth to improve health, mental health and well-being. It was built with extensive community consultation and fulfills the social support needs of youth participants at no cost. ${ }^{11}$ These measures were designed to enhance the quality of the program, while also encouraging completion on the part of the individual.

\section{Study Objectives}

The first objective was to determine program completion rates and independent risk indicators associated with program non-completion. The second objective was to determine the 12-week impact of the Healthy Kids Initiative (HKI) on aerobic fitness, depressed mood, and healthrelated quality of life. Weight loss was not an objective of the program in order to keep a positive focus on health and behaviors and to not discourage adherence.

\section{Materials and Methods}

\section{Intervention}

The Healthy Kids Initiative (HKI) offered a 12-week program to 2000 obese youth between the ages of 10 and 17 to achieve measurable changes in health, mental health and behavioral outcomes through increased physical activity, healthy eating, cognitive behavior education, and social support. The prospective, longitudinal cohort was offered in the cities of Moose Jaw, Regina, and Saskatoon, in the province of Saskatchewan, Canada, through the local not for profit YMCA fitness facilities.

The development of the 12-week HKI program benefited from community consultation with over 200 family physicians, pediatricians, cardiologists, internists, mayors, police chiefs, school board officials and teachers being consulted prior to intervention. Youth participants were referred by their own family physician or paediatrician.

\section{Participants}

Children and youth aged 10-17, who were obese as determined by their body mass index (score over 30), and deemed safe to participate in the intervention by their referring family doctor or pediatrician, were invited to participate. The only inclusion criteria was that the program must be safe for the participant to attend.

\section{Procedures}

Youth participated in daily physical activity five times per week supervised by a kinesiologist (who also monitored activity type and duration), group dietary education provided by a registered dietician once per week, group cognitive behaviour education provided by a social worker or psychologist once per week, along with social support from the health provider team. Each participant was asked to attend all sessions with a "buddy" for social support and each participant was asked to sign three social support contracts with family members or friends to encourage program completion. For example, if a youth was unsure as to who was providing transportation for the program, a family member or friend was asked to sign a transportation agreement prior to program initiation. Electronic swipe cards to enter the fitness facilities were used to capture program attendance of each participant.

Additional support was also provided through The Daily Difference smartphone app, which could be used at any time to help participants with goal setting, self-address 
mental health concerns, practice cognitive behavior skills, and also chat directly with health-care providers.

All youth signed an informed consent form prior to participating with a parent or guardian as a witness. The project was approved annually on ethical grounds by the Saskatchewan Health Authority (REB-18-63). This study was conducted in accordance with the Declaration of Helsinki.

\section{Measures}

The primary outcome of the study was to determine completion rates, and independent risk indicators associated with non completion. The secondary outcomes of the HKI were not weight loss, but instead focused on health outcome changes in aerobic fitness, depressed mood and health-related quality of life.

Self-esteem was measured with four questions taken from the Self-Description Questionnaire III, and asked participants to give an answer of false; mostly false; sometimes true, sometimes false; mostly true; or true to each of the four statements: 1) In general, I like the way I am, 2) Overall, I have a lot to be proud of, 3) A lot of things about me are good, and 4) I like the way I look. ${ }^{12}$ These items were used in multiple iterations of the National Longitudinal Survey of Children and Youth by Statistics Canada. $^{13}$

Health-related quality of life (HRQL) was measured using the shortened version of the Short-Form 36 Health Survey (SF-36). ${ }^{14}$ The SF-12 is a brief, psychometrically sound measure of quality of life. Scores measure two dimensions: physical and mental health. The SF-12 has comparable validity and reliability as its predecessor, ${ }^{15}$ which has been considered the generic measure of choice in obesity research by the United States Task Force on Developing Obesity Outcomes and Learning Standards (TOOLS). ${ }^{16}$

Depressed mood was measured using the 12-item Centre of Epidemiological Studies Depression scale (12item CES-D). The scale asks individuals to rate the frequency at which they have felt certain things in the past two weeks. The 12-item CES-D was used in the National Longitudinal Study of Children and Youth, and at the time established three categories of depressive symptoms among adolescents. Scores of $0-11$ indicated minimal depressed mood; scores of 12-20 indicated somewhat elevated depressed mood and a score of 21-36 indicated very elevated depressed mood. ${ }^{17}$
Aerobic Fitness was determined using the modified Canadian Aerobic Fitness Test (CAFT), which has been deemed as an acceptable measure of aerobic fitness with youth aged 10-15 years, having previously tested as comparable to the run/walk test. ${ }^{18}$ The modified CAFT protocol includes three minutes of stepping up and down a standardized staircase. Depending on heart rate at each three-minute interval, there are up to a maximum three stages (nine minutes of stepping maximal), with each stage increasing in pace. Participant heart rates are measured after each stage for 10 seconds, and results are presented as an indicator of maximum oxygen consumption adjusted for body weight $\left(\mathrm{mL} \times \mathrm{kg}^{-1} \times \mathrm{min}^{-1}\right)^{18}$ For males aged 8 to 14 years, the Canadian general population median is $57 \mathrm{~mL} \times\left(\mathrm{kg} \times \min ^{-1}\right)$. For males 15 to 19 years, the median is 53 . For females 8 to 14 years, the median is 50 , and for females 15 to 19 , the median is $43 .^{19}$

Dietary questions were taken from the National Longitudinal Survey of Children and Youth developed by Statistics Canada. ${ }^{13}$

Socioeconomic status was determined by parental education level, occupation, and neighborhood income (as determined by Statistics Canada census data by using postal code). ${ }^{20}$

All participants were screened at baseline and at the completion of the program (12 weeks).

\section{Analysis}

Using SPSS (v. 27) mean scores of each measure were calculated and compared using paired sample t-tests (significance tested at $\mathrm{p}<0.05)$. Categorical variables were compared via cross-tabulations to determine any significant associations between completers and non-completers and among those whose depressed mood improved after the program and those who remained depressed. Significant differences were determined using Chi-square test $(\mathrm{p}<0.05)$. For logistic regression analysis to determine independent risk indicators of program completion, the unadjusted effect of each covariate was determined and then entered one step at a time based on changes in the -2 log likelihood and the Wald test. ${ }^{21}$ The final results are presented as adjusted odds ratios with 95\% confidence intervals (CIs).

As part of a funding agreement with the Public Health Agency of Canada, an External Evaluation Specialist, and an External Evaluator, were hired. As such, a research manager and the Director of the Canadian Hub for Applied and Social Research (CHASR) at the University of Saskatchewan were 
contracted. This unit is governed by a management committee that includes a Chair, the Vice President Research of the University and the Dean or Executive Director from all 19 colleges on campus. At the end of each cohort, the Director of the CHASR was asked to sign a form to independently validate the accuracy of the data.

\section{Results}

Two thousand youths were referred to the program from January 1, 2019, to June 30, 2020, across the three sites. Five of the referrals never began the program. Among those who participated in the program, 1789 out of 1995 completed the 12 weeks (adherence rate of 89.7\%). The mean age was 14.5 years with a high proportion being 14 or older $(72.3 \%)$. Slightly over half $(52.4 \%)$ were female. The majority of participants' fathers (86.6\%) and mothers (75.5\%) were college or university educated. Almost all parents were employed, with $72.2 \%$ of fathers and $68.4 \%$ of mothers employed in non-professional positions, and $17.3 \%$ of fathers and $23.2 \%$ of mothers working in professional positions. Those who were unemployed were students $(10.5 \%$ of fathers and $8.4 \%$ of mothers). Finally, $86.6 \%$ of participants resided in middle-income neighborhoods, with others being from high income (11.3\%) and low income (2.1\%) neighborhoods. The percentage of Saskatchewan youth living in lowincome neighborhoods, according to the 2016 Census, was $17.8 \%$ and, as such, low-income youth were underrepresented in the sample of program participants. ${ }^{20}$ The demographic distribution of participants is presented in Table 1.

\section{Completion}

Program completion was defined as being an active participant up to follow-up testing as 12 weeks. Those who completed the program $(n=1789)$ were compared to those who did not $(n=206)$ across demographic variables, baseline depressed mood, and baseline modified CAFT scores. Prior to adjustment, age, gender, mother's education level, father's and mother's occupational status, and neighborhood income were all significantly associated with not completing the program (Table 2). Higher scores on the 12-item CES-D were also associated with non-completion, as well as lower baseline modified CAFT scores ( $<<0.001$ for both).

After binary logistic regression, three covariates were independently associated with program completion. Older age (odds ratio 3.07, 2.25-4.17 CI; $\mathrm{p}<0.001$ ), non-professional maternal occupation (odds ratio $1.84,1.22-2.78 \mathrm{CI} ; \mathrm{p}=0.004$ ) and being from a low-income neighborhood all had a negative association with program completion (odds ratio 9.37, 5-61-
Table I Demographics of Healthy Kids Initiative Participants, Groups I-5 ( $n=1789$ Out of 1995)

\begin{tabular}{|c|c|}
\hline Demographic Variables & n (\%) \\
\hline \multicolumn{2}{|l|}{ Age (mean): 14.5} \\
\hline \multicolumn{2}{|l|}{ Gender } \\
\hline Males & $852(47.6 \%)$ \\
\hline Females & 937 (52.4\%) \\
\hline \multicolumn{2}{|l|}{ Father education } \\
\hline University degree & 407 (22.8\%) \\
\hline College diploma & II 42 (63.8\%) \\
\hline High school diploma & $67(3.7 \%)$ \\
\hline Less than high school & I 73 (9.7\%) \\
\hline \multicolumn{2}{|l|}{ Mother education } \\
\hline University degree & $273(15.3 \%)$ \\
\hline College diploma & II 85 (66.2\%) \\
\hline High school diploma & $167(9.3 \%)$ \\
\hline Less than high school & $164(9.2 \%)$ \\
\hline \multicolumn{2}{|l|}{ Father occupation } \\
\hline Professional & $310(17.3 \%)$ \\
\hline Non-professional & 1292 (72.2\%) \\
\hline Student & 187 (I0.5\%) \\
\hline \multicolumn{2}{|l|}{ Mother occupation } \\
\hline Professional & $415(23.2 \%)$ \\
\hline Non-professional & I 224 (68.4\%) \\
\hline Student & I50 (8.4\%) \\
\hline \multicolumn{2}{|c|}{$\begin{array}{l}\text { Neighborhood income (as determined by census } \\
\text { data, postal code) }\end{array}$} \\
\hline High income & $203(11.3 \%)$ \\
\hline Middle income & I549 (86.6\%) \\
\hline Low income & $37(2.1 \%)$ \\
\hline
\end{tabular}

15.65 CI, $\mathrm{p}<001$; Table 3). Among those who completed the program, youth participants attended an average of 49 out of 60 supervised exercise sessions, 11 out of 12 dietary education sessions and 9 out of 12 cognitive behavior education sessions.

\section{Aerobic Fitness}

Participating in the exercise sessions of the program increased moderate to vigorous physical activity significantly. At baseline, the average amount of moderate physical activity that participants were reporting was 9.45 minutes per week, and 8.13 minutes of vigorous physical activity per week. After 12 weeks, the mean for moderate physical activity increased to 178.91 minutes per week. Vigorous physical activity increased to 226.13 minutes per week. Differences were statistically significant $(p<0.001)$. With the increased physical activity, participants also 
Table 2 Demographics, Depressed Mood (I2 Item CES-D) Score, and Aerobic Fitness (mCAFT) of Those Who Completed the Program at Baseline $(n=1789)$ Compared to Those Who Did Not Complete the Program $(n=206)$

\begin{tabular}{|c|c|c|c|}
\hline Variable & Completed Program n=I789 & Did Not Complete $\mathrm{n}=206$ & p-value \\
\hline Age (mean) & 14.5 years & 13.3 years & $<0.001$ \\
\hline 13 and younger & 581 (32.5\%) & $120(58.3 \%)$ & \\
\hline 14 and older & 1208 (67.5\%) & $86(41.7 \%)$ & \\
\hline Gender & & & 0.024 \\
\hline Males & $852(47.6 \%)$ & 81 (39.3\%) & \\
\hline Females & 937 (52.4\%) & $125(60.7 \%)$ & \\
\hline Father education & & & 0.159 \\
\hline Post-secondary & 1549 (86.6\%) & I7I (83.0\%) & \\
\hline High school or less & $240(13.4 \%)$ & 35 (17.0\%) & \\
\hline Mother education & & & $<0.001$ \\
\hline Post-secondary & | 458 (8I.5\%) & 0 & \\
\hline High school or less & $331(18.5 \%)$ & $206(100 \%)$ & \\
\hline Father occupation & & & 0.015 \\
\hline Professional & $310(17.3 \%)$ & $22(10.7 \%)$ & \\
\hline Non-professional & 1479 (82.7\%) & $184(89.3 \%)$ & \\
\hline Mother occupation & & & 0.005 \\
\hline Professional & $415(23.2 \%)$ & $30(14.6 \%)$ & \\
\hline Non-professional & 1374 (76.8\%) & $184(85.4 \%)$ & \\
\hline Neighborhood income (as determined by census data, postal code) & & & $<0.001$ \\
\hline High/middle income & 1752 (97.9\%) & I7I (83.0\%) & \\
\hline Low income & $37(2.1 \%)$ & 35 (17.0\%) & \\
\hline I2 item CES-D Mean (SD) & $1.47(5.36)$ & $21.38(4.14)$ & $<0.001$ \\
\hline No depressed mood & 345 (19.3\%) & $21(10.2 \%)$ & \\
\hline Depressed mood & 1444 (80.7\%) & $184(89.3 \%)$ & \\
\hline Missing & 0 & I (0.5\%) & \\
\hline $\begin{array}{l}\text { Modified CAFT Mean } \\
\text { (SD) }\end{array}$ & $\begin{array}{l}35.84 \mathrm{~mL}^{*} \mathrm{~kg}^{-1} * \mathrm{~min}^{-1} \\
(4.80)\end{array}$ & $\begin{array}{l}29.86 \mathrm{~mL}^{*} \mathrm{~kg}^{-1} * \mathrm{~min}^{-1} \\
(6.54)\end{array}$ & $<0.001$ \\
\hline
\end{tabular}

experienced an increase in aerobic fitness. Mean modified

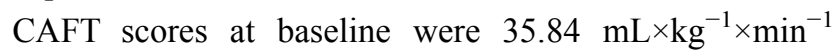
$(\mathrm{SD}=4.80)$ and after 12 weeks, the mean score was $55.72 \mathrm{~mL} \times \mathrm{kg}^{-1} \times \min ^{-1}(\mathrm{SD}=7.49)$. Again, this difference was statistically significant $(p<0.001)$. In all, $76.5 \%$ of participants increased their CAFT from below the national average for their gender and age group to meet or exceed the national average after 12 weeks.

\section{Health-Related Quality of Life (HRQL)}

HRQL increased significantly from baseline to 12 weeks (Table 4). Mean scores across all dimensions increased by $44.4 \%(p<0.001)$ with dimensional increases from 23.1\% (Role Physical) to 58.1\% (Physical Functioning); with all improvements being statistically significant $(p<0.001)$. Reports of very good to excellent general health increased from $5.6 \%$ to $57.4 \%$ after 12 weeks, while poor health decreased from $19.6 \%$ of participants to almost none of the participants $(0.2 \%)$. Any interference of normal work or activities in the past four weeks decreased from $94.4 \%$ of the participants at baseline to $69.5 \%$, and that proportion was split over "a little bit" and "moderately" only.

\section{Self-Esteem}

Responses for each self-esteem variable were assigned a value $(0=$ False; $1=$ Mostly False; $2=$ Sometimes true, sometimes false; $3=$ Mostly True; and $4=$ True). Each statement is worded positively, and higher scores are indicative of a higher sense of self-esteem. Mean scores on each of the four items were compared at baseline and after 12 weeks. Scores on all items improved, and the difference was statistically significant across participants (Table 5). 
Table 3 Independent Covariates Associated with Non-Completion of the HKI at 12 Weeks. Reference Categories: Age = 13 and Younger; Maternal Occupation $=$ Professional; Neighborhood $=$ High/Medium Income

\begin{tabular}{|l|l|l|l|}
\hline Variable & Adjusted Odds Ratio* & 95\% Cl & p-value \\
\hline $\begin{array}{l}\text { Age } \\
\text { Older age }\end{array}$ & $3.07(2.90)$ & $2.26-4.17$ & $<0.00$ I \\
\hline $\begin{array}{l}\text { Mother occupation } \\
\text { Non-professional/other }\end{array}$ & $1.84(1.77)$ & $1.22-2.78$ & 0.004 \\
\hline $\begin{array}{l}\text { Neighborhood Income } \\
\text { Low Income }\end{array}$ & $9.37(23.34)$ & $5.61-15.65$ & $<0.001$ \\
\hline
\end{tabular}

Note: *The unadjusted odds ratios for age, mother occupation and neighborhood income appear in brackets beside the adjusted odds ratios.

Abbreviations: HKI, Healthy Kids Initiative; SF-12, Short-form I2; CES-D, Center for Epidemiological Studies Depression; mCAFT, modified Canadian Aerobic Fitness Test.

Table 4 Health-Related Quality of Life (SF-12) at Baseline Compared to I2-Week HKI Program Completion

\begin{tabular}{|c|c|c|c|c|c|}
\hline Health-Related Quality of Life (SF-I 2) & Baseline Mean (SD) & I 2-Week Mean (SD) & Absolute Change & $\%$ Change & p-value \\
\hline Overall & $23.4(2.4 I)$ & $33.8(2.95)$ & +10.4 & $44.4 \%$ & $<0.001$ \\
\hline Physical functioning & $3.1(0.68)$ & $4.9(0.91)$ & +1.8 & $58.1 \%$ & $<0.001$ \\
\hline Role Physical & $2.6(0.67)$ & $3.2(0.85)$ & +0.6 & $23.1 \%$ & $<0.001$ \\
\hline Role Emotional & $2.3(0.65)$ & $3.2(0.75)$ & +0.9 & $39.1 \%$ & $<0.001$ \\
\hline Mental Health & $5.5(1.06)$ & $7.2(1.30)$ & +1.7 & $30.9 \%$ & $<0.001$ \\
\hline
\end{tabular}

\section{Depressed Mood}

Depressed mood mean scores decreased overall from baseline to follow-up (21.47 decreased to 17.4 over 12 weeks; $\mathrm{p}<0.001$ ). At the start of the program, only $1.6 \%$ of participants had no indication of depressed mood, at the end of the program, the percentage increased to $7.2 \%$. What is more, is that the percentage of participants with very elevated depressed mood decreased from $60.4 \%$ to $23.6 \%$. The percentage of participants whose mood improved at least $10 \%$ from baseline to follow-up was $65.2 \%$. Increases of $25 \%$ or more were observed among $26.6 \%$ of participants (Table 6).

Table 5 Self-Esteem Scores and Distribution at Baseline Compared to I2-Week HKI Program Completion

\begin{tabular}{|c|c|c|c|}
\hline Self-Esteem Variable & Baseline n (\%) & I 2-Week n (\%) & p-value \\
\hline In general, I like the way I am [Mean (SD)] & $1.65(0.64)$ & $2.66(0.72)$ & $<0.001$ \\
\hline False, mostly false & $679(37.4 \%)$ & $108(6.0 \%)$ & \\
\hline Sometimes true, sometimes false & 1036 (57.9\%) & $544(30.4 \%)$ & \\
\hline True, mostly true & $85(4.7 \%)$ & 1137 (63.5\%) & \\
\hline Overall, I have a lot to be proud of [Mean (SD)] & $1.67(0.67)$ & $3.24(0.65)$ & $<0.001$ \\
\hline False, mostly false & $646(36.1 \%)$ & $5(0.3 \%)$ & \\
\hline Sometimes true, sometimes false & $1025(57.3 \%)$ & $193(10.8 \%)$ & \\
\hline True, mostly true & 118 (6.6\%) & I59| (88.9\%) & \\
\hline A lot of things about me are good [Mean (SD)] & $1.76(0.68)$ & $2.22(0.7 \mathrm{I})$ & $<0.001$ \\
\hline False, mostly false & $566(31.7 \%)$ & $289(16.1 \%)$ & \\
\hline Sometimes true, sometimes false & $1050(58.7 \%)$ & $827(46.2 \%)$ & \\
\hline True, mostly true & $173(9.7 \%)$ & $673(37.6 \%)$ & \\
\hline I like the way I look [Mean (SD)] & $0.45(0.66)$ & $2.49(0.7 I)$ & $<0.001$ \\
\hline False, mostly false & 1639 (91.6\%) & $6(0.3 \%)$ & \\
\hline Sometimes true, sometimes false & 146 (8.2\%) & $933(52.2 \%)$ & \\
\hline True, mostly true & $4(0.2 \%)$ & $850(47.6 \%)$ & \\
\hline
\end{tabular}




\section{Discussion}

The Healthy Kids Initiative is a multidisciplinary, communitybased behavioral modification program for overweight and obese adolescents. The program has had promising shortterm results in improving health-related quality of life, selfesteem, depressed mood, and aerobic fitness. However, these results are only evident if participants can successfully complete the program. The completion rate of HKI is nearly $90 \%$, which is higher than other multi-disciplinary weight loss or behavior modification interventions targeted at youth. ${ }^{10}$ For example, other multidisciplinary programs that include physical activity and dietary intervention have had completion rates ranging from $53 \%$ at six months, ${ }^{22} 58 \%$ at 20 weeks, ${ }^{23}$ and $73 \%$ at 12 weeks. $^{24}$

Other studies of adolescent-focused weight loss or behavior modification interventions have found a number of predictors of adherence. For example, a systematic review of barriers and facilitators to community-based behavior modification programs for overweight/obese adolescents found that a family-centered approach to weight loss, supportive program staff, practical sessions (rather than solely educational sessions), social support, a behavioral modification focused approach, and parental concern were important variables. ${ }^{25}$

Another systematic review reviewed ten studies of weight-loss interventions for adolescents and found a number of variables associated with dropout, including (but not limited to) higher baseline BMI, obesity-related medical conditions, depressive symptoms, behavioral problems, and not having Medicaid insurance. ${ }^{10}$

In our study, factors that increased the risk of program non-completion included living in a low-income neighborhood. Living in a low-income neighborhood is a lower socioeconomic status indicator as well as having a mother with a non-professional (possibly lower-paying occupation, with less flexibility). Lower socioeconomic status has been repeatedly demonstrated as a risk indicator for poorer health outcomes in youth (including in obesity). ${ }^{26}$
Its effect here on program completion could be through multiple pathways, such as struggling to access reliable transportation. Limited transportation has been associated with non-completion in other weight reduction programs targeting obese/overweight adolescents. According to one systematic review, lack of access to transportation was reported in five different studies of obese youth as a contributor to drop-out. ${ }^{25}$

The other factor contributing to program non-completion is older age. This has been found to be associated with dropout and non-adherence in the literature. ${ }^{23,27}$ For example, in a study of 183 obese and overweight adolescents participating in a multidisciplinary, community-based weight loss program, those aged younger than 15 years were $60 \%$ less likely to drop out of the program. ${ }^{23}$ In a 2004 study of 212 obese youths participating in a clinical program, only $45 \%$ completed and older participants were $64 \%$ more likely to drop out of the program. ${ }^{27}$

Altogether, HKI had high rates of completion with positive improvements in health, mental health and well-being. The program's requirement of a buddy, three signed social support contracts, and cognitive behavior education, are all critical elements of the program. Social support has been found to be an important part of maintaining physical activity changes in adults, but there is little literature that assesses this directly in youth participating in weight reduction or behavioral modification interventions. Although many programs adopt group-based strategies (as per recommendations), ${ }^{11}$ few studies appear to assess this directly. One study found that having friends and peers present while engaging in physical activity motivated obese boys. ${ }^{28}$ Additionally, among obese youth, perception of better peer support is associated with higher HRQoL. ${ }^{29}$

\section{Limitations}

The study design was a prospective longitudinal cohort and not a randomized controlled trial (RCT). After

Table 6 Percentage of HKI Participants Across Three Levels of Depressed Mood Symptomatology at Baseline Compared to I2-Week Completion

\begin{tabular}{|c|c|c|c|c|c|}
\hline \multicolumn{2}{|l|}{ Depressed Mood Levels } & \multicolumn{2}{|l|}{ Baseline n (\%) } & \multicolumn{2}{|c|}{ I 2-Week n (\%) } \\
\hline \multirow{3}{*}{\multicolumn{2}{|c|}{$\begin{array}{l}\text { No depressed mood } \\
\text { Somewhat elevated depressed mood } \\
\text { Very elevated depressed mood }\end{array}$}} & \multirow{3}{*}{\multicolumn{2}{|c|}{$\begin{array}{l}29(1.6) \\
680(38) \\
1080(60.4)\end{array}$}} & \multirow{3}{*}{\multicolumn{2}{|c|}{$\begin{array}{l}128(7.2) \\
1239(69.3) \\
422(23.6)\end{array}$}} \\
\hline & & & & & \\
\hline & & & & & \\
\hline Depressed Mood (CES-D I2) & Baseline Mean (SD) & I 2-week Mean (SD) & Absolute Change & $\%$ Change & p-value \\
\hline Overall & $21.47(5.36)$ & $17.40(4.36)$ & -4.07 & $19 \%$ & $<0.001$ \\
\hline
\end{tabular}


community consultation, it was clear that an RCT study design would not be supported. As well, after community consultation, it was clear that a control group without intervention would not be supported. This is another limitation of our study. However, the lack of use of an RCT means that the findings are associations, and cannot be thought of as implying causation. The study does have a 12-month long-term follow-up but those results are not available yet.

\section{Conclusion}

The HKI is a community-based initiative targeting behavior modification for overweight and obese youth with a high completion rate and early success in improving health, mental health and behavioral outcomes. Knowing the risk factors for non-completion of the first five waves will allow for program modification to target at-risk participants to help complete the program.

\section{Acknowledgments}

Special thanks to Director Jason Disano for being the External Evaluator of the HKI.

\section{Disclosure}

The authors report no conflicts of interest in this work. The HKI had external funding from the Public Health Agency of Canada (agreement number 1819-HQ-000094). The views expressed herein do not necessarily represent the views of the Public Health Agency of Canada.

\section{References}

1. Rao DP, Kropac E, Do MT, Roberts KC, Jayaraman GC. Childhood overweight and obesity trends in Canada. Health Promot Chronic Dis Prev Can. 2016;36(9):194-198. doi:10.24095/hpcdp.36.9.03

2. Government of Canada. Tackling Obesity in Canada: childhood obesity and excess weights rates in Canada. Public Health Agency of Canada 2018. Available from: https://www.canada.ca/en/public-health /services/publications/healthy-living/obesity-excess-weight-ratescanadian-children.html. Accessed September 24, 2020.

3. Jing L, Binkley CM, Suever JD, et al. Cardiac remodeling and dysfunction in childhood obesity: a cardiovascular magnetic resonance study. J Cardiovasc Mag Resonance. 2016;18(1):28. doi:10.1186/s12968-016-0247-0

4. Woolf SH, Chapman DA, Buchanich JM, Bobby KJ, Zimmerman EB, Blackburn SM. Changes in midlife death rates across racial and ethnic groups in the United States: systemic analysis of vital statistics. BMJ. 2018;362:k3096. doi:10.1136/bmj.k3096

5. Lindberg L, Hagman E, Danielsson P, Marcus C, Persson M. Anxiety and depression in children and adolescent with obesity: a nationwide study in Sweden. BMC Med. 2020;18(30). doi:10.1186/s12916-0201498-z

6. Mameli C, Krakauer JC, Krakauer NY, et al. Effects of a multidisciplinary weight loss intervention in overweight and obese children and adolescents: 11 years of experience. PLoS One. 2017;12 (7):e0181095. doi:10.1371/journal.pone.0181095
7. Kolotourou M, Radley D, Gammon C, Smith L, Chadwick P, Sacher PM. Long-term outcomes following the MEND 8-13 child weight management program. Childhood Obesity. 2015;11 (3):325-330. doi:10.1089/chi.2014.0092

8. Al-Khudairy L, Loveman E, Colquitt JL, et al. Diet, physical activity and behavioural interventions for the treatment of overweight or obese adolescents aged 12-17 years. Cochrane Database Syst Rev. 2017;6:Art. No.: CD012691.

9. Dao HH, Frelut ML, Oberlin F, Peres G, Bourgeios P, Navarro J. Effects of a multidisciplinary weight loss intervention on body composition in obese adolescents. Int $J$ Obesity. 2004;28:290-299. doi:10.1038/sj.ijo.0802542

10. Skelton JA, Beech BM. Attrition in pediatric weight management. Obesity Rev. 2011;12:e273-e281. doi:10.1111/j.1467-789X.2010.0 0803.x

11. Alberga AS, Medd ER, Adamo KB, et al. Top 10 practical lessons learned from physical activity interventions in overweight and obese children and adolescents. Appl Phyisol Nutr. 2013;38:249-258.

12. Marsh HW, O'Neill R. Self description questionnaire III: the construct validity of multidimensional self-concept ratings by late adolescents. J Educ Meas. 1984;21(2):153-174. doi:10.1111/j.17453984.1984.tb00227.x

13. Statistics Canada. National longitudinal survey of children and youth cycle 4 Survey Instruments 2000-2001 Book 2 - Teacher, Principal and Youth (10-17 year-olds). Available from: https://www23.statcan.gc.ca/ $\mathrm{imdb} / \mathrm{p} 3$ Instr.pl?Function=getInstrumentList\&Item_Id=33638\&UL= AV. Accessed September 172020.

14. Ware JE, Kosinski M, Keller SD. SF-36 Physical and Mental Health Summary Scales: A Users' Manual. Boston, MA: The Health Institute; 1994.

15. Jr. JE, Kosinski M, Keller SD. A 12-item Short-Form Health Survey: construction of scales and preliminary tests of reliability and validity. Med Care. 1996;34(3):220-233. doi:10.1097/00005650-19960300000003

16. Kolotkin RL, Meter K, Wiliams GR. Quality of life and obesity. Obes Rev. 2001;2:219-229. doi:10.1046/j.1467-789X.2001.00040.x

17. Poulin C, Hand D, Boudreau B. Validity of a 12-item version of the CES-D used in the National Longitudinal Study of Children and Youth. Chronic Dis Can. 2005;26(2-3):65-72.

18. Garcia AW, Zakrajsek JS. Evaluation of the Canadian Aerobic Fitness Test with 10-15 year old children. Ped Exercise Sci. 2000;12:300-311. doi:10.1123/pes.12.3.300

19. Government of Canada. Median predicted maximal aerobic power $(\mathrm{mL} \cdot$ $(\mathrm{kg} \cdot \mathrm{min})^{-1}$ ), by sex and age, household population aged 8 to 19 years, Canada, March 2007 to February 2009. Statistics Canada 2015 Available from: https://www150.statcan.gc.ca/n1/pub/82-003-x/2010001/article/ 11065/figures/fig1-eng.htm;. Accessed September 26, 2020.

20. Government of Canada. Census in Brief: children living in low income households. Statistics Canada. 2017. Catalogue no. 98-200X2016012 Available from: https://www12.statcan.gc.ca/censusrecensement/2016/as-sa/98-200-x/2016012/98-200-x2016012-eng. pdf;. Accessed September 26, 2020.

21. Rothman KJ, Greenland S. Modern Epidemiology. 2nd ed ed. Philadelphia, PA: Lippincott Williams and Wilkins; 1998.

22. Ehrmann DE, Sallinen BJ, IglayReger HB, Gordon PM, Woolford SJ. Slow and steady: readiness, pretreatment weekly strengthening activity, and pediatric weight management program completion. Child Obes. 2013;9(3):193-199. doi:10.1089/chi.2013.0006

23. Fidelix YL, Cazuza de Farias J Jr, Lofrano-Prado MC, Guerra RLF, Cardel M, Do Prado WL. Multidisciplinary intervention in obese adolescents: predictors of dropout. Einstein. 2015;13(3):388-394. doi:10.1590/S1679-45082015AO3339

24. Fagg J, Cole TJ, Cummins S, et al. After the RCTL who comes to a family-based intervention for childhood overweight or obesity when it is implemented at scale in the community? Epidemiol Comm Health. 2015;69:142-148. doi:10.1136/jech-2014-204155 
25. Kelleher E, Davoren MP, Harrington JM, Shiely F, Perry IJ, McHugh SM. Barriers and facilitators to initial and continued attendance at community-based lifestyle programmes among families of overweight and obese children: a systematic review. Obes Rev. 2017;18(2):183-194. doi:10.1111/obr.12478

26. Schreier HM, Chen E. Socioeconomic status and the health of youth: A multilevel, multi domain approach to conceptualizing pathways. Psych Bull. 2013;139(3):606-654. doi:10.1037/a0029416

27. Zeller M, Kirk S, Claytor R, et al. Predictors of attrition from a pediatric weight management program. $J$ Pediatr. 2004;144:466-470. doi:10.1016/j.jpeds.2003.12.031
28. Salvy SJ, Bowker JC, Germeroth L, Barkley J. Influence of peers and friends on overweight/obese youths' physical activity. Exerc Sport Sci Rev. 2012;34(2):217-225.

29. Herzer M, Zeller MH, Rausch JR, Modi AC. Perceived social support and its association with obesity-specific health-related quality of life. $J$ Dev Behav Pediatr. 2011;32(2):188-195. doi:10.1097/DBP.0b $013 \mathrm{e} 318208 \mathrm{f} 576$

\section{Publish your work in this journal}

Patient Preference and Adherence is an international, peer-reviewed, open access journal that focusing on the growing importance of patient preference and adherence throughout the therapeutic continuum. Patient satisfaction, acceptability, quality of life, compliance, persistence and their role in developing new therapeutic modalities and compounds to optimize clinical outcomes for existing disease states are major areas of interest for the journal. This journal has been accepted for indexing on PubMed Central. The manuscript management system is completely online and includes a very quick and fair peer-review system, which is all easy to use. Visit http:// www.dovepress.com/testimonials.php to read real quotes from published authors. 